\title{
Efeito alelopático do extrato alcoólico do cravo-da-índia e eugenol
}

\author{
PAULO MAZZAFERA ${ }^{1}$
}

(recebido: 20 de março de 2002; aceito: 19 de março de 2003)

\begin{abstract}
Allellopathic effects of the alcoholic extract of clove and eugenol). Eugenol is a volatile phenolic compound, being the major constituent of clove oil. In this study it was observed that clove ethanolic extract and pure eugenol had an allelopathic effect on the germination of several seeds, as well as that some of these seedlings sprayed with the clove extract showed a lower dry mass accumulation. It was not observed long distance inhibition of seed germination due to volatilization of eugenol.
\end{abstract}

Key words - Allelopathy, eugenol, phenol, Syzygium aromaticum

RESUMO - (Efeito alelopático do extrato alcoólico do cravo-da-índia e eugenol). Eugenol é um composto fenólico volátil e é o principal consituinte do óleo extraído do cravo-da-índia. Neste estudo verificou-se que extrato etanólico do cravo-da-índia e eugenol puro possuem efeito alelopático, inibindo a germinação de sementes de várias plantas, assim como diminuindo o crescimento de algumas delas quando aspergidas com o extrato. Não se verificou efeito alelopático de eugenol a longa distância, em função de sua característica volátil.

Palavras-chave - Alelopatia, eugenol, fenol, Syzygium aromaticum

\section{Introdução}

A árvore produtora do cravo-da-índia (Syzygium aromaticum (L.) Merr. \& Perry) é endêmica nas Molucas do Norte (Arquipélago de Molucas Indonésia), tendo sido disseminada pelos alemães durante a colonização pelas outras ilhas do arquipélago, assim como para outros países. Atualmente Zanzibar e Madagascar são os principais produres de cravo-daíndia, seguidos pela Indonésia.

O cravo-da-índia é a gema floral seca sendo usado principalmente como condimento na culinária, devido ao seu marcante aroma e sabor, conferido por um composto fenólico volátil, o eugenol. Nas folhas ele chega a representar aproximadamente $95 \%$ do óleo extraído (Raina et al. 2001) e no cravo também é o principal componente do óleo, variando de 70 a $85 \%$ (Brown \& Morra 1995, Brown et al. 1991, Ortiz 1992). Outros componentes dessa fração são acetato de eugenol (15\%) e $\beta$-cariofileno ( 5 a $12 \%$ ), que juntos com eugenol somam $99 \%$ do óleo. Uma vez que óleo no cravo pode exceder $15 \%$, conclui-se que a quantidade de eugenol no cravo pode chegar próxima a esse valor.

Sua obtenção comercial é feita principalmente a partir do cravo. O eugenol é muito usado na

1. Universidade Estadual de Campinas, Instituto de Biologia, Departamento de Fisiologia Vegetal, Caixa Postal 6109, 13083-970 Campinas, SP, Brasil.pmazza@unicamp.br odontologia como componente de seladores e outros produtos antissépticos de higiene bucal, tendo comprovado efeito bactericida (Cai \& Wu 1996, Chong et al. 1997, Kaplan et al. 1999, Shapiro et al. 1994). Essa aplicação comercial direta tem como conseqüência vários estudos sobre a obtenção do óleo essencial do cravo-da-índia (Clifford et al. 1999, Rovio et al. 1999). Além disso, o eugenol tem sido empregado para a produção de outros fenólicos, tal como a vanilina (Priefert et al. 2001).

Alguns trabalhos mostraram que eugenol ou extratos de $S$. aromaticum apresentam atividade nematicida (Tsao \& Yu 2000, Walker \& Melin 1996), inseticida (El-Hag et al. 1999), antiviral (Yukawa et al. 1996), bactericida (Dorman \& Deans 2000, Nascimento et al. 2000, Ouattara et al. 1997) e fungicida (Delespaul et al. 2000). Os efeitos bactericida e fungicida do eugenol talvez expliquem porque a pulverização de sementes de cravo com fungicidas não melhora a germinação (Maeda et al. 1991).

O presente trabalho surgiu da observação de que vasos semeados com algumas sementes de cravo-daíndia não possuíam ervas daninhas, que cresciam abundantemente em vasos vizinhos, com outras plantas semeadas. Por exemplo, trevinho (Oxalis sp.), uma erva bastante agressiva e com rápida disseminação, não proliferou nos vasos contendo as sementes de cravoda-índia. Assim, o presente trabalho teve como objetivo estudar o efeito inibitório do cravo-da-índia e de seu componente, eugenol, sobre a germinação e o crescimento de plântulas. 


\section{Material e métodos}

O material usado nas extrações é proveniente de um craveiro de aproximadamente 30 anos, crescendo no Município de Campinas, SP. A muda que originou esta árvore foi obtida no Instituto Agronômico de Campinas, da antiga Seção de Plantas Aromáticas. As gemas florais foram coletadas e colocadas para secar à sombra.

A extração, a partir dos cravos secos, foi feita em etanol $80 \%$ (37 g em $200 \mathrm{~mL})$ à temperatura ambiente, durante $24 \mathrm{~h}$ e sob agitação constante. Após filtração em duas camadas de papel de filtro, os cravos foram submetidos a nova extração nas mesmas condições. Os filtrados foram reunidos, o solvente foi eliminado utilizando-se um evaporador rotatório (a $35^{\circ} \mathrm{C}$ ) e o resíduo solubilizado em $300 \mathrm{~mL}$ de etanol $66 \%$. Alíquotas de $20 \mathrm{~mL}$ foram guardadas em freezer a $-20{ }^{\circ} \mathrm{C}$ para os ensaios e dosagens descritas a seguir.

Os ensaios de germinação foram feitos em placas de Petri com $5 \mathrm{~cm}$ de diâmetro tendo duas camadas de papel de filtro no fundo. Nelas, distribuiram-se, uniformemente, $2 \mathrm{~mL}$ de extrato diluído ou etanol $66 \%$ (controle). O extrato foi diluído para as concentrações de 7,75, 31 e $62 \mathrm{mg} \cdot \mathrm{mL}^{-1}$, utilizando-se etanol $66 \%$. As placas foram deixadas abertas durante dois dias para completa evaporação do álcool, para depois receberem as sementes e $2,5 \mathrm{~mL}$ de água destilada. A germinação foi acompanhada durante quatro dias, considerando-se germinada a semente com pelo menos $1 \mathrm{~mm}$ de radicela. Nos ensaios feitos com eugenol puro (Sigma), este foi diluído em etanol $66 \%$, gerando soluções que coincidiam com as quantidades de eugenol encontradas no ensaio com extrato diluído. A montagem do ensaio foi então feita da mesma maneira que o ensaio descrito anteriormente. No ensaio em que se verificou o efeito do potencial osmótico dos extratos na germinação, utilizou-se polietilenoglicol 6000 (PEG-6000) para produzir os potenciais de -0,5, -1,0 e -2,0 bars (Michel \& Kaufmann 1973). A conferência dos potenciais dessas soluções bem como as determinações dos potenciais dos extratos diluídos foram feitas com psicrômetro de par termoelétrico (Câmara C-52, Wescor), conectados a um microvoltímetro de ponto de orvalho (HR-33T, Wescor). Para o ensaio em que se verificou o efeito de vapores do eugenol sobre a germinação, sementes foram postas para germinar em placas de Petri com água e então transferidas sem as tampas para saco plástico. No mesmo saco plástico colocou-se uma placa de Petri de $5 \mathrm{~cm}$ de diâmetro, contendo $2 \mathrm{~mL}$ de eugenol puro e adicionou-se água fora das placas para evitar ressecamento das mesmas. Os sacos foram vedados firmemente.

Em todos os testes citados utilizaram-se três repetições. As placas com as sementes germinando foram mantidas em temperatura ambiente (aproximadamente $25^{\circ} \mathrm{C}$ ) e após dois dias de colocadas para germinar, adicionou-se mais $1 \mathrm{~mL}$ de água a cada placa. Nos ensaios foram utilizadas sementes de tomate (Lycopersicum esculentum Mill.), beijo (Impatiens balsamina L.), crotalaria (Crotalaria spectabilis L.), rabanete
(Raphanus sativus L.), trigo (Triticum aestivum L.) e alface (Lactuca sativa L.).

No ensaio sobre o efeito do extrato de cravo no crescimento de plantas, conduzido em casa de vegetação, sementes de beijo, trigo, rabanete, azevém (Lolium multiflorum Lam.), milho (Zea mays L.), arnica (Arnica lanceolata Nutt.), rumex (Rumex obtusifolius L.) e mostarda (Sinapis alba L.) foram germinadas em vasos de $500 \mathrm{~mL}$, contendo uma mistura de terra e areia, na proporção de 1:1. Após 15 dias da semeadura foi feito um desbaste para que cada vaso ficasse com 40 plantas, exceção feita ao tomate, arnica e milho, com 15 plantas. Aos 20 dias a superfície do vaso foi protegida com algodão e as plantas pulverizadas com soluções de cravo diluídas para as concentrações de 1,23 e $6,2 \mathrm{mg} \cdot \mathrm{mL}^{-1}$. Estas soluções foram preparadas eliminando-se o etanol dos extratos originais em evaporador rotatório, adicionando-se o volume adequado de água para atingir as concentrações desejadas. Para cada $100 \mathrm{~mL}$ de solução final, adicionaram-se quatro a cinco gotas de tween 20. As plantas controle foram pulverizadas com água contendo tween 20. A pulverização foi feita até ser notada uma boa umidificação das folhas. Após uma semana, as plantas foram pulverizadas com as mesmas soluções, repetindo-se o mesmo por mais duas semanas. Ao final de um mês da primeira pulverização, as plantas foram colhidas dos vasos, cortando-se na base do caule, e secas em estufa $80^{\circ} \mathrm{C}$ por dois dias para determinação da massa seca. Cada vaso constituiu uma repetição e foram feitas três repetições para cada planta. Para comparação dos dados de germinação, eles foram transformados em arco-seno e analisados por ANOVA.

O conteúdo de fenóis solúveis no extrato etanólico de cravo-da-índia foi determinado colorimetricamente (Swain \& Hillis 1959), utilizando-se ácido clorogênico (ácido 5-cafeoilquínico) como padrão de referência. O eugenol foi determinado no extrato de cravo-da-índia por cromatografia líquida de alta eficiência (CLAE), com um sistema Shimadzu de cromatografia. A separação dos componentes do extrato foi feita em coluna $\mathrm{C}_{18}$ de fase reversa, com um gradiente de 0 a $100 \%$ de metanol em solução aquosa a $0,5 \%$ de ácido acético, durante 60 minutos e com fluxo de $0,8 \mathrm{~mL} \cdot \mathrm{min}^{-1}$. A detecção dos compostos eluindo da coluna foi feita com detetor de UV operando em $254 \mathrm{~nm}$ e o sinal integrado em estação de trabalho da Packard. A identificação de eugenol foi feita por co-injeção de amostra com padrão e também por comparação do espectro de UV do pico de eugenol coletado nas amostras com o do padrão puro.

\section{Resultados}

Para a maioria das sementes, os extratos de cravoda-índia nas concentrações de 31 e $62 \mathrm{mg} \cdot \mathrm{mL}^{-1}$ causaram forte inibição da germinação (figura 1). A semente mais sensível ao extrato foi a de tomate, que 

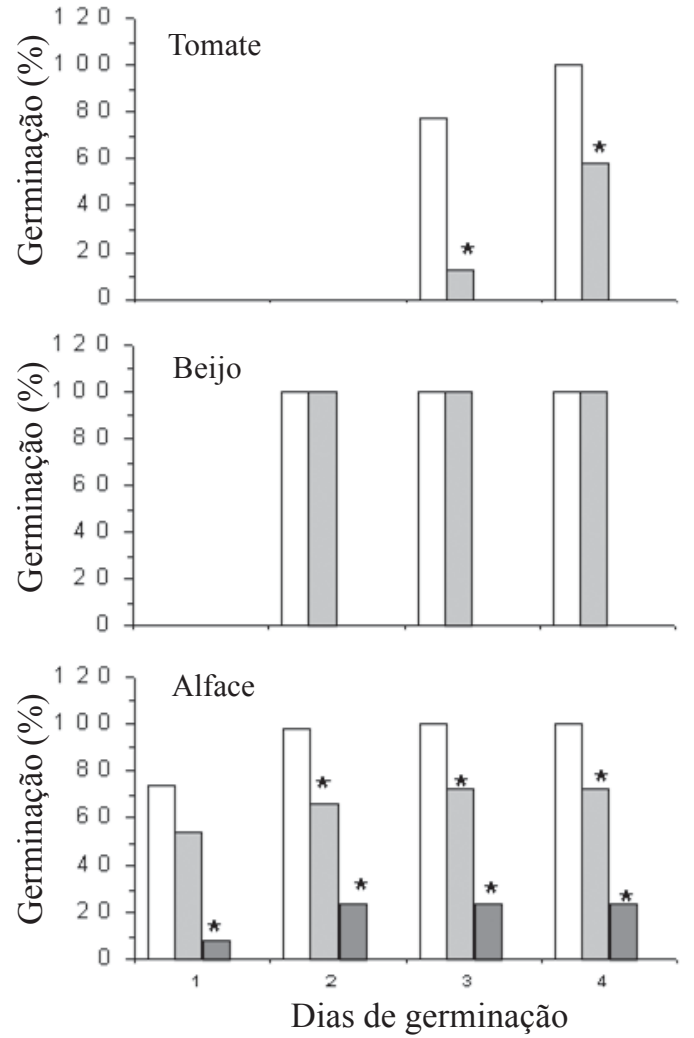

A

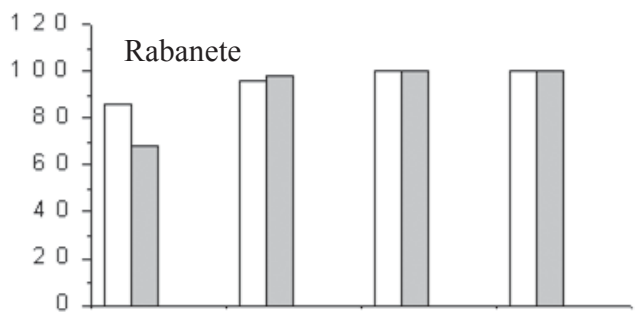

B

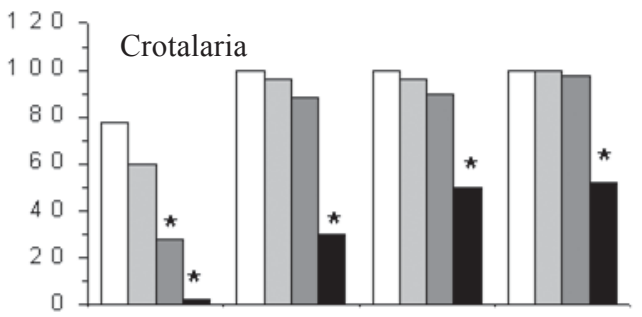

C

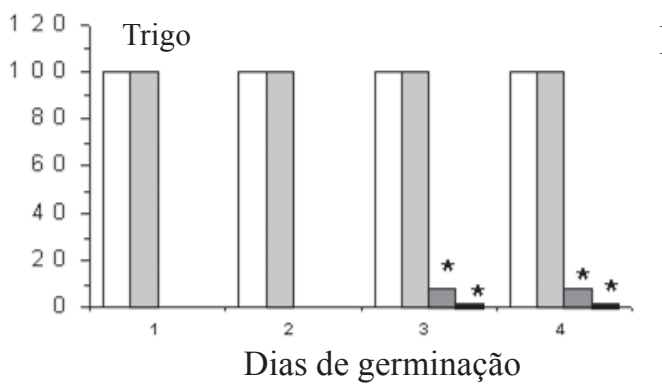

D

$\mathbf{E}$

$\mathbf{F}$

Figura 1. Germinação de sementes expostas a soluções de extrato de cravo-da-índia nas concentrações de 7,75; 31 e 62 mg.mL $L^{-1}$. A germinação é apresentada como porcentagem do controle. Asterisco indica diferença do controle a $\mathrm{p} \leq 0,05$. $\square$ Água; $\square 7,75$ mg.mL ${ }^{-1}$; 31 mg.mL ${ }^{-1} ; 62$ mg.mL-1.

Figure 1. Seed germination in clove extracts at $7.75 ; 31$ and $62 \mathrm{mg} \cdot \mathrm{mL}^{-1}$. Germination is shown as \% of the control. * indicates statistical difference from the control at $\mathrm{p} \leq 0.05$. $\square$ Water; $\square 7.75 \mathrm{mg} \cdot \mathrm{mL}^{-1} ; \square 31 \mathrm{mg} \cdot \mathrm{mL}^{-1} ; \mathbf{\square} 62 \mathrm{mg} \cdot \mathrm{mL}^{-1}$.

teve a germinação diminuída mesmo com extrato $7,75 \mathrm{mg} \cdot \mathrm{mL}^{-1}$ (figura 1A). Por outro lado, crotalária foi a menos sensível, pois após quatro dias a germinação era praticamente igual entre água e diluições de $31 \mathrm{e}$ $7,75 \mathrm{mg} \cdot \mathrm{mL}^{-1}$. Com o extrato $62 \mathrm{mg} \cdot \mathrm{mL}^{-1}$, a germinação foi aproximadamente $50 \%$ do controle (figura $1 \mathrm{E}$ ). Algumas sementes de alface e trigo germinaram na presença de extratos menos diluídos (figuras 1C, F).

A quantificação de eugenol por CLAE mostrou que no ensaio anterior as quantidades colocadas do fenol eram de 1,$04 ; 4,16$ e $8,32 \mathrm{mg}$ por placa de Petri, para os extratos de 7,$75 ; 31$ e $62 \mathrm{mg} . \mathrm{mL}^{-1}$, respectivamente. O cálculo por massa extraída mostrou que a concentração de eugenol no cravo-da-índia usado era de $67,1 \mathrm{mg} \cdot \mathrm{g}^{-1}$. O cromatograma de CLAE mostra bem a predominância de eugenol no extrato alcoólico (figura 2). A dosagem colorimétrica de fenóis, usando ácido clorogênico como padrão de referência, indicou concentração de $187,7 \mathrm{mg} . \mathrm{g}^{-1} \mathrm{de}$ fenóis totais. Logo, usando estes valores e os de CLAE, o eugenol representaria aproxima- damente $35 \%$ dos fenóis extraídos do cravo-da-índia.

Com base nos dados de CLAE montou-se um ensaio de germinação, no qual adicionou-se eugenol em etanol $66 \%$, de forma a igualar as quantidades encontradas nos extratos diluídos (figura 3). Observaram-se, neste caso, efeitos inibitórios mais pronunciados do que aqueles verificados com os extratos de cravo-da-índia. Com exceção da crotalária, que teve sementes germinadas na concentração $7,75 \mathrm{mg} \cdot \mathrm{mL}^{-1}$ (figura $3 \mathrm{E}$ ), houve inibição em todos os outros casos.

A determinação dos potenciais osmóticos das soluções diluídas de extrato de cravo-da-índia para as concentrações $7,75,31$ e $62 \mathrm{mg} \cdot \mathrm{mL}^{-1}$, usadas no primeiro ensaio, mostraram potenciais de $-0,59,-1,21$ e -1,99 bars, respectivamente. No ensaio com PEG-6000 nos potenciais de $-0,5,-1,0$ e $-2,0$ bars, em algumas espécies, foi observada inibição inicial da germinação, principalmente com os potenciais menores, mas, após quatro dias, a germinação igualava ao controle, com água (figura 4). 


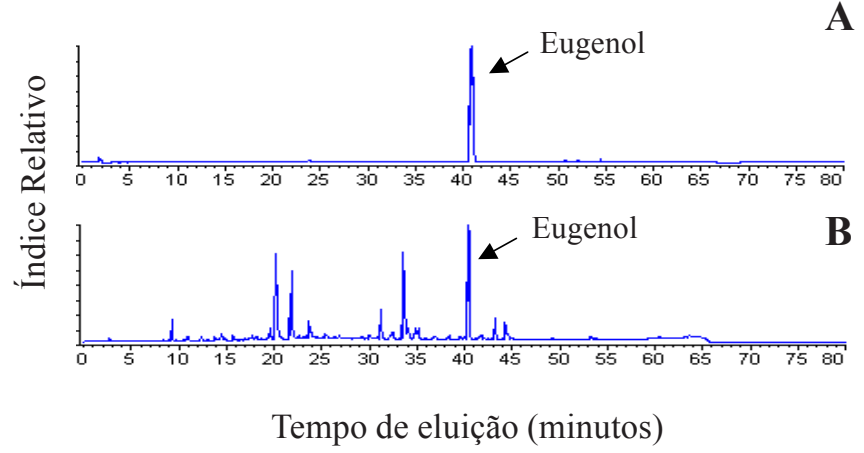

Figura 2. Cromatografias obtidas por CLAE de fase reversa de eugenol puro (A) e de extrato alcoólico de cravo-da-índia (B).

Figure 2. Reverse-phase HPLC chromatography of pure eugenol (A) and clove extract (B).

O ensaio realizado para verificar o efeito dos vapores de eugenol sobre a germinação de sementes não mostrou diferenças com os controles, em cujos sacos plásticos não se colocou eugenol (dados não apresentados).

Ainda que não tenha sido significativo em todos os casos, de modo geral houve a tendência do extrato de cravo-da-índia na concentração de $6,2 \mathrm{mg} \cdot \mathrm{mL}^{-1}$ causar a redução de acúmulo de massa em plântulas pulverizadas semanalmente (figura 5). Pouca ou nenhuma inibição no crescimento ocorreu com o extrato a $1,23 \mathrm{mg} \cdot \mathrm{mL}^{-1}$.

\section{Discussão}

Compostos fenólicos correspondem à classe de metabólitos secundários na qual se encontra a maior parte dos compostos apontados como tendo atividade alelopática, indo desde fenóis simples até taninos de estrutura complexa (Rice 1984). Entre os fenóis, poucos são voláteis, como o eugenol. Entre compostos voláteis com efeito alelopático são conhecidos alguns terpenos (Friedman \& Waller 1983, Rice 1984) e, em crucíferas, os produtos da hidrólise dos glucosinolatos, uma classe de compostos contendo enxofre e glucose. Estes, quando degradados hidroliticamente por mirosinase, geram produtos voláteis, entre eles os isotiocianatos, que possuem acentuado efeito alelopático sobre uma série de espécies vegetais (Brown et al. 1991).

Eugenol é volátil e poderia ter efeito alelopático à distância. Apesar de ter sido verificado que isso não ocorre, ficou demonstrado o efeito alelopático do extrato de cravo-da-índia quando em contato direto com sementes. Ensaios com eugenol puro mostraram que ele participa desse efeito. O eugenol foi o principal composto identificado por CLAE, representando $35 \%$ dos fenóis extraídos do cravo-da-índia. É provável que esse valor possa ser ainda maior, uma vez que a extração empregada neste trabalho não foi exaustiva.

Vários estudos na literatura mostraram que extratos de plantas podem inibir a germinação de sementes não necessariamente devido aos seus constituintes químicos, mas sim em função do potencial osmótico do extrato (Wardle et al. 1992, Haugland \& Brandsaeter 1996). No presente estudo, apesar do experimento com PEG-6000 ter mostrado atraso na germinação das sementes no primeiro dia, todas apresentaram alta taxa de germinação nos dias seguintes, diferentemente do observado com extratos de eugenol ou mesmo com eugenol puro. Isso indica que o efeito observado não se deveu à inibição pelo potencial osmótico.

A comparação entre o ensaio com extratos de cravo-da-índia e com eugenol puro mostrou uma inibição maior no segundo caso, sendo possível que outros componentes do extrato tenham estimulado a germinação. Além do eugenol várias outras substâncias foram separadas por CLAE.

Também foram observadas variações em função da espécie testada. Chamou atenção a alta taxa de germinação de C. spectabilis. Ainda que seja inferido que essa espécie tenha sementes maiores do que as outras, é possível perceber que o alface, cujas sementes são pequenas, teve sementes germinando em extratos diluídos a $31 \mathrm{mg} \cdot \mathrm{mL}^{-1}$. Assim, é provável que o modo de inibição seja diferente para cada espécie.

Variações na sensibilidade também foram observadas no ensaio em que plantas foram pulverizadas com extratos diluídos de cravo-da-índia. Por exemplo, proporcionalmente ao controle, azevém, tomate e arnica tiveram o crescimento menos afetado que rumex, beijo e milho.

Variações de resposta foram observadas, também, por Shettel \& Balke (1983), que expuseram plantas cultivadas e ervas daninhas a cinco compostos classificados pela literatura como alelopáticos. Foram feitas aplicações em diferentes estádios de crescimento, desde germinação até pós-emergência. Verificou-se que a efetividade em inibir germinação ou diminuir o acúmulo de massa seca dependia do composto, da quantidade aplicada, da espécie receptora e da época de aplicação, sugerindo diferentes modos de ação.

O presente trabalho mostra, pela primeira vez, o efeito alelopático de extratos de cravo-da-índia e eugenol na germinação e crescimento de plantas. Exceto os dados 

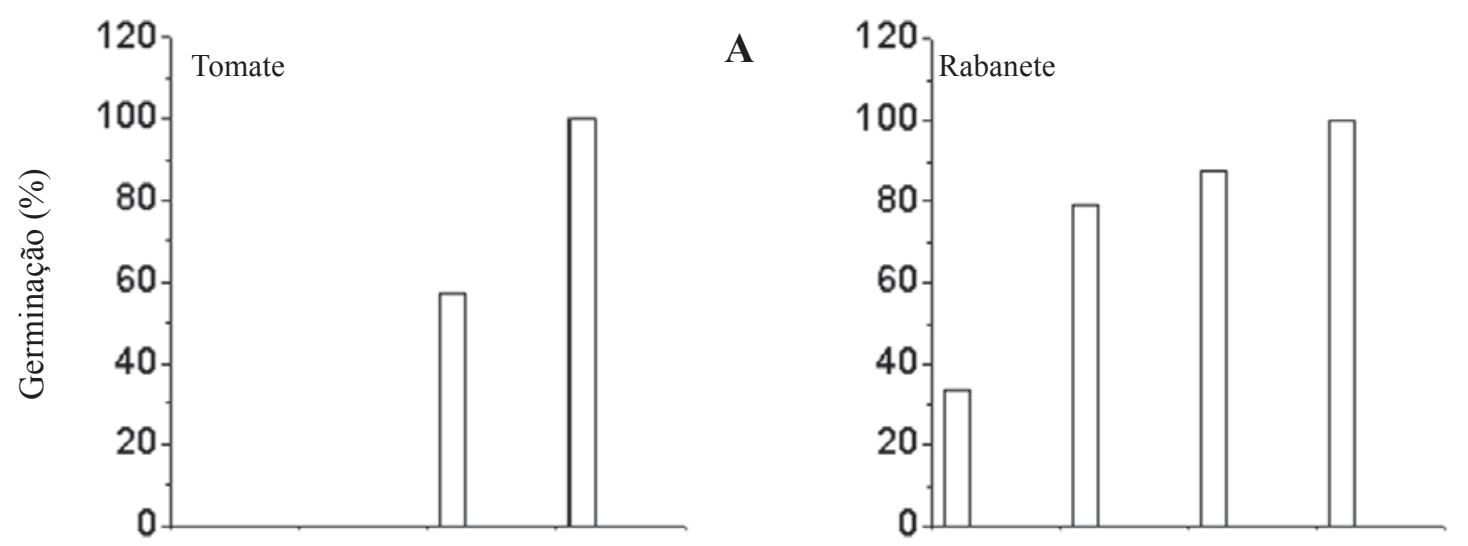

D
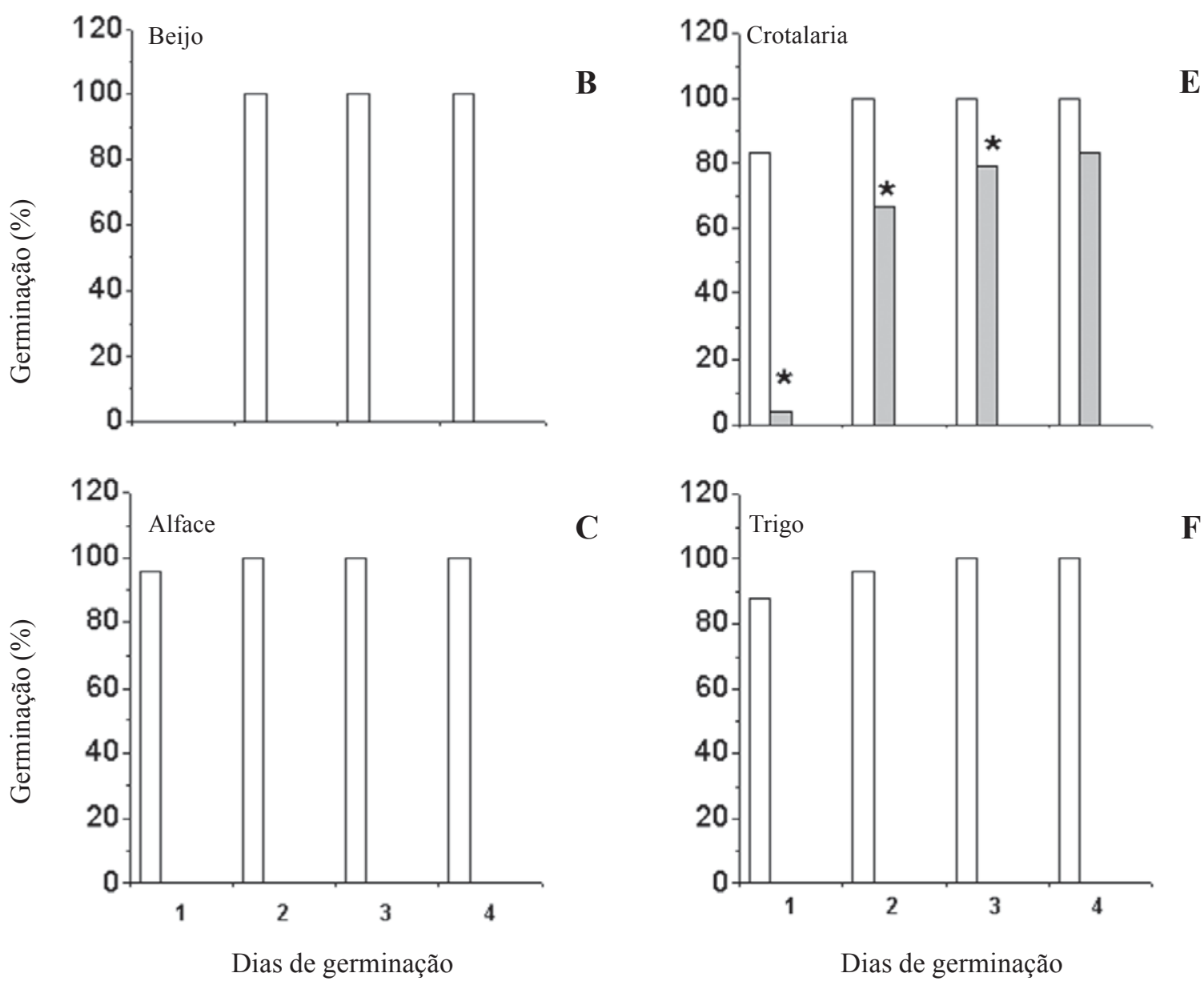

Figura 3. Germinação de sementes expostas ao eugenol, diluído de tal modo que as quantidades coincidissem com aquelas do extrato de cravo-da-índia diluído para as concentrações de 7,75; 31 e $62 \mathrm{mg} \cdot \mathrm{mL}^{-1}$. A germinação é apresentada como porcentagem do controle. Asterisco indica diferença do controle a $\mathrm{p} \leq 0,05$. $\square$ Água; $\square 7,75 \mathrm{mg} \cdot \mathrm{mL}^{-1}$; $\square 1 \mathrm{mg} \cdot \mathrm{mL}^{-1} ; \mathbf{\square} 62 \mathrm{mg} \cdot \mathrm{mL}^{-1}$.

Figure 3. Germination of seeds in eugenol solutions adjusted to the same concentration as in the clove extracts at 7.75; 31 and $62 \mathrm{mg} \cdot \mathrm{mL}^{-1}$. Germination is shown as $\%$ of the control. * indicates statistical difference from the control at $\mathrm{p} \leq 0.05$. $\square$ Water; $7.75 \mathrm{mg} \cdot \mathrm{mL}^{-1} ; \quad 31 \mathrm{mg} \cdot \mathrm{mL}^{-1} ; \mathbf{\square} 62 \mathrm{mg} \cdot \mathrm{mL}^{-1}$. 

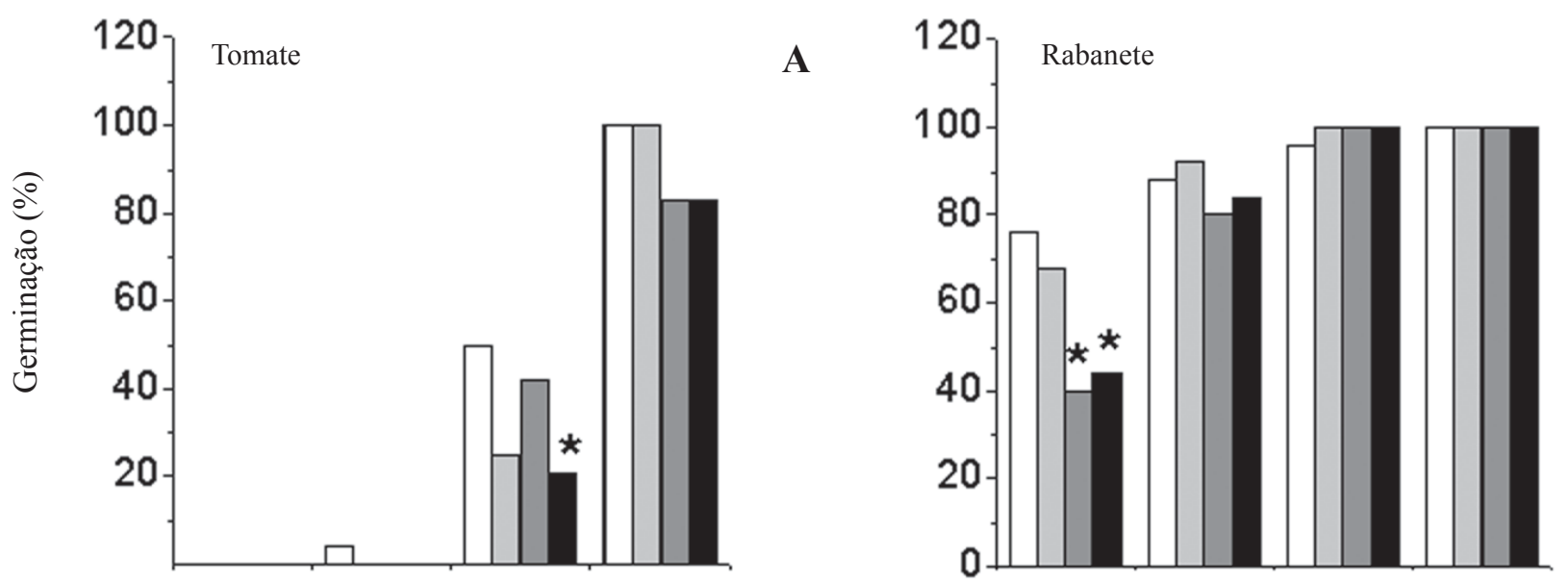

D

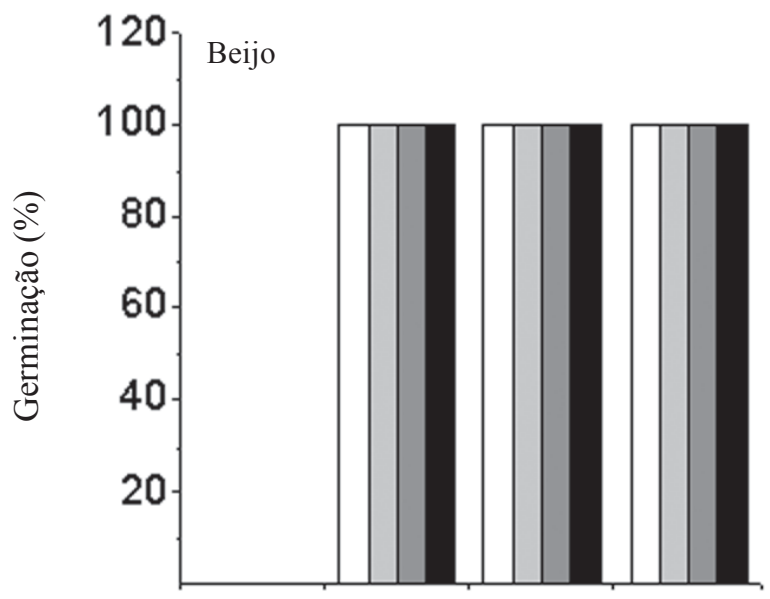

B
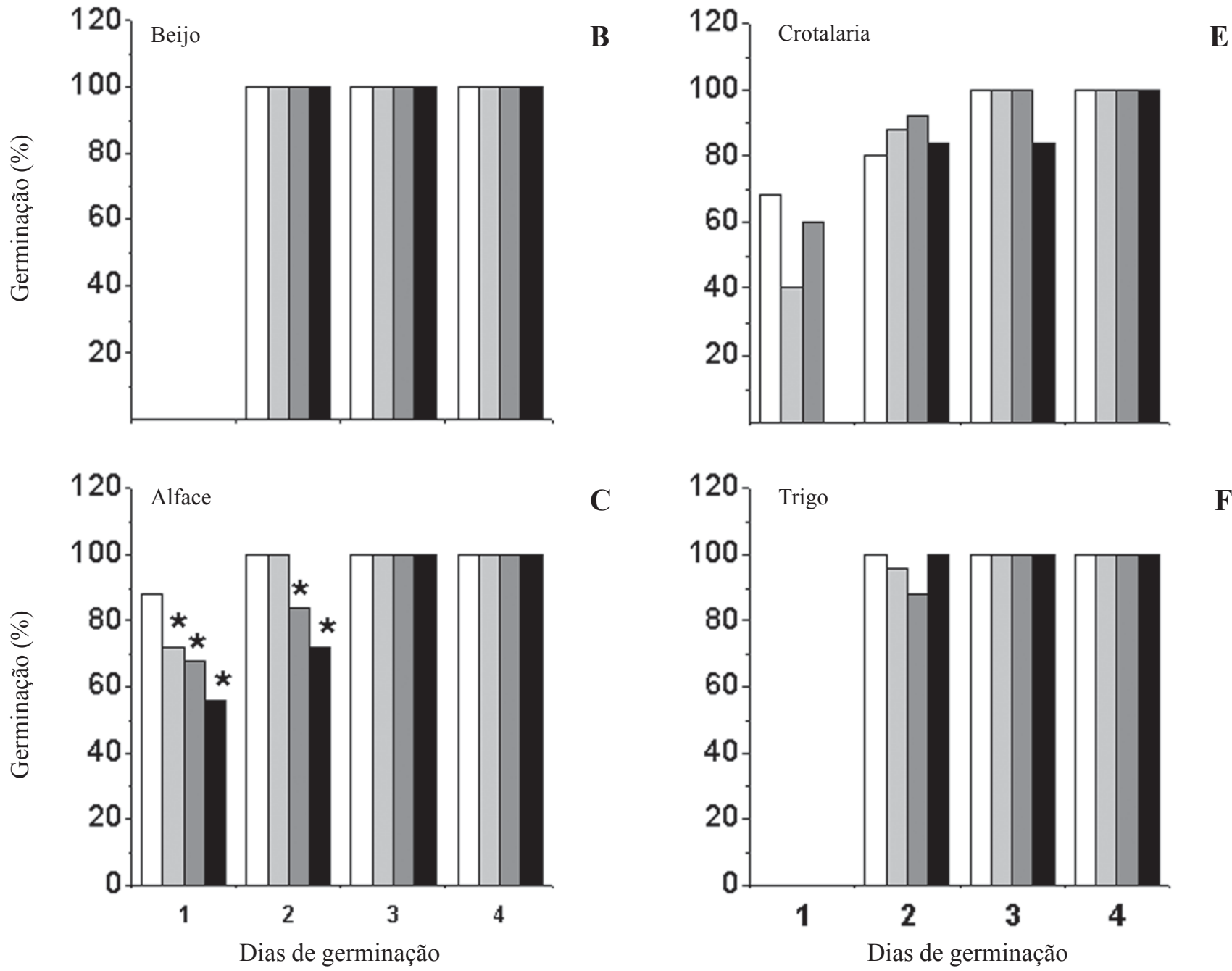

Figura 4. Efeito do PEG-6000 nas germinação de sementes. Asterisco indica diferença do controle a $\mathrm{p} \leq 0,05$. $\square$ Água; $\square-0,5$ bar; $-1,0$ bar; $-2,0$ bar.

Figure 4. Influence of PEG-6000 on the germination of seeds. ${ }^{*}$ indicates statistical difference from the control at $\mathrm{p} \leq 0.05$. $\square$ Water; $\square-0.5$ bar; $\square-1.0$ bar; $\mathbf{\square}-2.0$ bar. 


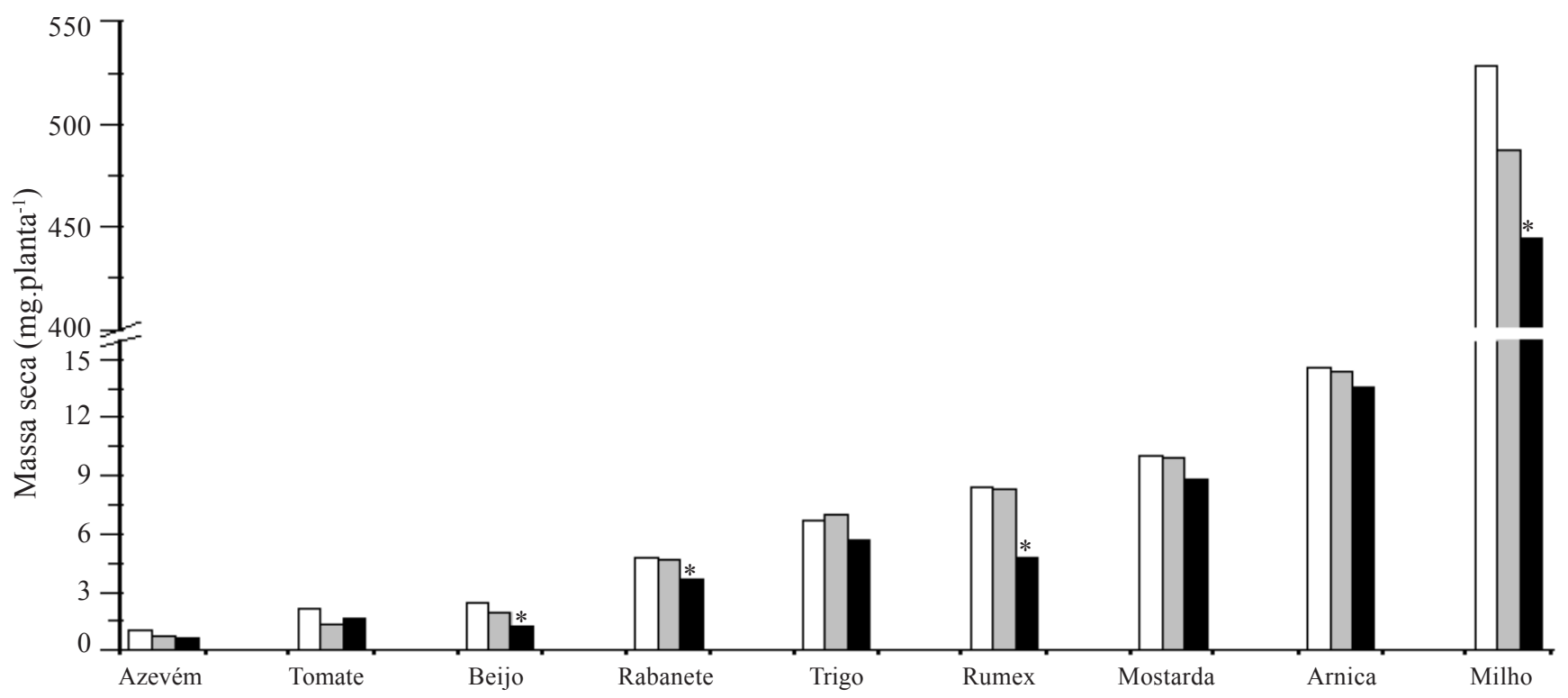

Figura 5. Massa seca da parte aérea de plantas aspergidas com soluções de cravo-da-índia nas concentrações de 1,23 e $6,2 \mathrm{mg} \cdot \mathrm{mL}^{-1}$. Asterisco indica diferença do controle a $\mathrm{p} \leq 0,05$. $\square$ Água; $\square 1,23 \mathrm{mg} \cdot \mathrm{mL}^{-1} ; \mathbf{\square}$ 6,2 mg.mL $\mathrm{mL}^{-1}$.

Figure 5. Shoot dry mass of plants sprayed with clove extracts at 1.23 e $6.2 \mathrm{mg} . \mathrm{mL}^{-1}$. * indicates statistical difference from the control at $\mathrm{p} \leq 0.05$. $\square$ Water; $\square 1.23 \mathrm{mg} \cdot \mathrm{mL}^{-1} ; \quad 6.2 \mathrm{mg} \cdot \mathrm{mL}^{-1}$.

de Tsao \& Yu (2000) e Walker \& Melin (1996) sobre o efeito de eugenol em nematóides de plantas, não são de nosso conhecimento outros trabalhos nessa linha de estudo. Logo, seria interessante investigar o efeito alelopático do eugenol depositado no solo pela queda e lavagem das folhas do craveiro, uma vez que essas apresentam grande concentração desse fenol (Raina et al. 2001). Da mesma maneira, seria interessante estudar se esse fenol volátil tem alguma importância protetora contra o ataque de insetos, uma vez que é conhecida popularmente a recomendação de se colocarem cravos em açucareiros para evitar formigas.

Agradecimentos - $\mathrm{O}$ autor agradece à Dulcinéia Pereira de Souza pelo excelente auxílio técnico durante a condução deste trabalho e à Dra. Laurecir Gomes pelo fornecimento das amostras de cravo-da-índia.

\section{Referências bibliográficas}

BROWN, P.D. \& MORRA, M.J. 1995. Glucosinolatecontaining plant tissues as bioherbicides. Journal of Agricultural and Food Chemistry 43:3070-3074.

BROWN, P.D., MORRA, M.J., MCCAFFREY, J.P., AULD, D.L. \& WILLIAMS III, L. 1991. Allelochemicals produced during glucosinolate degradation in soil. Journal of Chemical Ecology 17:2021-2034.
CAI, L.N. \& WU, C.D. 1996. Compounds from Syzygium aromaticum possessing growth inhibitory activity against oral pathogens. Journal of Natural Products 59:987-990.

CHONG, B.S., FORD, T.R.P. \& KARIYAWASAM, S.P. 1997. Short-term tissue response to potential root-end filling materials in infected root canals. International Endodontic Journal 30:240-249.

CLIFFORD, A.A., BASILE, A. \& AL-SAIDI, S.H.R. 1999. A comparison of the extraction of clove buds with supercritical carbon dioxide and superheated water. Fresenius Journal of Analytical Chemistry 364:635-637.

DELESPAUL, Q., BILLERBECK, V.G., ROQUES, C.G., MICHEL, G., MARQUIER-VINUALES, C. \& BESSIERE, J.M. 2000. The antifungal activity of essential oils as determined by different screening methods. Journal of Essential Oil Research 12:256-266.

DORMAN, H.J.D. \& DEANS, S.G. 2000. Antimicrobial agents from plants: antibacterial activity of plant volatile oils. Journal of Applied Microbiology 88:308-316.

EL-HAG, E.A., EL-NADI, A.H. \& ZAITOON, A.A. 1999. Toxic and growth retarding effects of three plant extracts on Culex pipiens larvae (Diptera: Culicidae). Phytotherapy Research 13:388-392.

FRIEDMAN, J. \& WALLER, G.R. 1983. Seeds as allelopathic agents. Journal of Chemical Ecology 9:1107-1117. 
HAUGLAND, E. \& BRANDSAETER, L. 1996. Experiments on bioassay sensitivity in the study of allelopathy. Journal of Chemical Ecology 22:1845-1859.

KAPLAN, A.E., PICCA, M., GONZALEZ, M.I., MACCHI, R.L. \& MOLGATINI, S.L. 1999. Antimicrobial effect of six endodontic sealers: an in vitro evaluation. Endodontics and Dental Traumatology 15:42-45.

MAEDA, J.A., BOVI, M.L.A., BOVI, O.A. \& LAGO, A.A. 1991. Germination of clove seeds - effect of temperature, fruit pulp and fungicide treatment. Pesquisa Agropecuária Brasileira 26:893-899.

MICHEL, B.E. \& KAUFMANN, M.R. 1973. The osmotic potential of polyethilene glycol 6000. Plant Physiology 51:914-916.

NASCIMENTO, G.G.F., LOCATELLI, J., FREITAS, P.C. \& SILVA, G.L. 2000. Antibacterial activity of plant extracts and phytochemicals on antibiotic-resistant bacteria. Brazilian Journal of Microbiology 31:247-256.

ORTIZ, E.L. 1992. The Encyclopedia of Herbs, Spices, and Flavourings. Dorling Kindersley Publishers, London.

OUATTARA, B., SIMARD, R.E., HOLLEY, R.A., PIETTE, G.J.P. \& BEGIN, A. 1997. Antibacterial activity of selected fatty acids and essential oils against six meat spoilage organisms. International Journal of Food Microbiology 37:155-162.

PRIEFERT, H., RABENHORST, J. \& STEINBUCHEL, A. 2001. Biotechnological production of vanillin. Applied Microbiology Biotechnology 56:296-314.

RAINA, V.K., SRIVASTAVA, S.K., AGGARWAL, K.K., SYAMASUNDAR, K.V. \& KUMAR, S. 2001. Essential oil composition of Syzygium aromaticum leaf from Little Andaman, India. Flavour Fragrance Journal 16:334-336.

RICE, E.L. 1984. Alellopathy, $2^{\text {nd }}$ ed. Academic Press, Orlando.
ROVIO, S., HARTONEN, K., HOLM, Y., HILTUNEN, R. \& RIEKKOLA, M.L. 1999. Extraction of clove using pressurized hot water. Flavour Fragrance Journal 14:399-404.

SHAPIRO, S., MEIER, A. \& GUGGENHEIM, B. 1994. The antimicrobial activity of essential oils and essential oil components towards oral bacteria. Oral Microbiology Immunology 9:202-208.

SHETTEL, N.L. \& BALKE, N.E. 1983. Plant growth response to several allelopathic chemicals. Weed Science 31:293-298.

SWAIN, T. \& HILLIS, W.E. 1959. The phenolic constituents of Prunus domestica. I. The quantitative analysis of phenolic constituents. Journal of the Science of Food and Agriculture 10:63-68.

TSAO, R. \& YU, Q. 2000. Nematicidal activity of monoterpenoid compounds against economically important nematodes in agriculture. Journal of Essential Oil Research 12:350-354.

WALKER, J.T. \& MELIN, J.B. 1996. Mentha x piperita, Mentha spicata and effects of their essential oils on Meloidogyne in soil. Journal of Nematology 28:629-635.

WARDLE, D.A., NICHOLSON, K.S. \& AHMED, M. 1992. Comparison of osmotic and allelopathic effects of grass leaf extracts on grass seed-germination and radicle elongation. Plant and Soil 140:315-319.

YUKAWA, T.A., KUROKAWA, M., SATO, H., YOSHIDA, Y., KAGEYAMA, S., HASEGAWA, T., NAMBA, T., IMAKITA, M., HOZUMI, T. \& SHIRAKI, K. 1996. Prophylactic treatment of cytomegalovirus infection with traditional herbs. Antiviral Research 32:63-70. 